\title{
The effects of a dual adaptive strategy with gesture recognition and perceived exertion on training efficiency of elders' functional fitness
}

I-Chun Hung ${ }^{1 *} \mathbb{D}$, Shih-Chieh Wang ${ }^{2}$, Yueh-Hui Vanessa Chiang ${ }^{3}$, Junfeng Yang ${ }^{4}$, Kinshuk ${ }^{5}$ and Nian-Shing Chen ${ }^{6}$

* Correspondence: ichung. academic@gmail.com

'Department of Industrial \& Systems Engineering, University of

Washington, Seattle, WA 98195, USA

Full list of author information is available at the end of the article

\section{Abstract}

Training efficiency is important for functional fitness training because it assures the trainees receive appropriate training to meet their needs of skill formation. With the support of technologies, the functional fitness training process can be adapted to suit each elder's physical conditions. This study proposes a dual adaptive strategy for adjusting exercise intensity levels based on the objective assessments and subjective feedback to balance body and mind conditions. An adaptive exercising system was also developed by using gesture recognition and perceived exertion to adjust exercise intensity levels and help the elders receive more appropriate training. The results show that the dual adaptive strategy proven to be able to provide better balance (body and mind) and improve training efficiency for elders' functional fitness training at their own paces while gaining a satisfied training experience.

Keywords: Functional fitness, Dual adaptive strategy, Exercise intensity, Gesture recognition, Perceived exertion

\section{Research highlights}

1. Little has been done on designing adaptive exercising system for elder people to improve functional fitness.

2. A dual adaptive strategy was designed for adjusting exercise intensity levels based on the objective assessments and subjective feedback to balance between body and mind conditions.

3. An adaptive exercising system was also developed by using gesture recognition and perceived exertion to adjust exercise intensity levels and help the elders receive more appropriate training.

4. The dual adaptive strategy was proven to be able to provide better balance and improve training efficiency for elders' functional fitness training at their own paces.

\section{Introduction}

Physical fitness represents the ability of an individual to perform physical activities in terms of body movement with increased energy expenditure (U.S. Department of

(c) The Author(s). 2019 Open Access This article is distributed under the terms of the Creative Commons Attribution 4.0 International License (http://creativecommons.org/licenses/by/4.0/), which permits unrestricted use, distribution, and reproduction in any medium, provided you give appropriate credit to the original author(s) and the source, provide a link to the Creative Commons license, and indicate if changes were made. 
Health and Human Services, 1996). Health-related fitness particularly focuses on the health goals including cardiorespiratory fitness, muscular strength, skeletal muscular endurance, flexibility, and body composition. On the other hand, performance-related fitness emphasizes on the skills pertaining to athletic abilities in terms of skeletal muscular power, speed, agility, balance, coordination, and reaction time (Hoeger, 1988; Pate, 1983). Functional fitness is regarded as the extension of health-related fitness with the goal of functional training that elders can manage to complete activities of their daily life safely without undue fatigue and improve their quality of life by taking eight measurable attributes into consideration (i.e., cardiorespiratory fitness, muscular strength, skeletal muscular endurance, flexibility, balance, coordination, reaction time, and body composition) (Brill, 2004; Rikli \& Jones, 1999). Hence, keeping a moderate and appropriate exercise intensity is the key success factor of training, instead of having excessive exercise intensity which may lead to exercise injury during the physical fitness training of the elders (Gillis \& Stewart, 2005). Therefore, the key success factor of training manifests the importance of training adequacy which indicates whether the trainees receive appropriate training to meet their needs of skill formation (Green, Felstead, Gallie, Inanc, \& Jewson, 2013). A related study also explicitly pointed out that elders' functional fitness training content must be tailored according to the state of individual physical capability for a better training (American College of Sports et al., 2009). When the elders exercise, the intensity of a new activity needs to be increased gradually by focusing on proper execution, body awareness and comfort level (Pruitt, 2003). Therefore, a training strategy that can adjust exercise intensity according to the physical capacity and status of each elder during the training process is needed.

By taking the advantage of technologies, professional trainers can help elders conduct exercise activities to improve their physical fitness efficiently, and enhance the quality of daily life corresponding to elders' needs (Chang, Lai, \& Hwang, 2018; Chung, Lai, \& Hwang, 2019; Fozard, Rietsema, Bouma, \& Graafmans, 2000). Ijsselsteijn, Nap, de Kort, and Poels (2007) pointed out that a complicated training system may be difficult for elders to operate, and use of technologies is likely to impose a detrimental impact on their dynamic vision, bodily motions, and cognitive load. In order to cope with such operational issues, the studies utilize natural user interface technologies to provide elders with more intuitive and simple operations in rehabilitation processes through voice recognition and motion-sensing techniques (Aarhus, Grönvall, Larsen, \& Wollsen, 2011; Maillot, Perrot, \& Hartley, 2012; Yang et al., 2018). Technologies can function as supporting tools in a safe training process for lowering the anxious mental state and developing a habit of regular exercises (Biddle \& Mutrie, 2007; McAuley et al., 2000). If a training system does not provide exercise support to match individual elder's physical conditions with a suitable user interface design, elders would need more reaction time during the system operation, which affects training efficiency eventually due to the difference of each elder's physical conditions (Nap, Kort, \& IJsselsteijn, 2009).

Researchers have also demonstrated that gesture recognition can be potentially beneficial in the physical training of elders (Aarhus et al., 2011; Maillot et al., 2012). For example, the Nintendo ${ }^{\circ}$ WiiFit was utilized to train elders for falls intervention and to improve elders' balance as well as their self-perceived confidence (Williams, Soiza, Jenkinson, \& Stewart, 2010). This study also pointed out that the training performance is affected by inadequate increase in exercise intensity levels because all elders exercise 
with a fixed adjustment strategy during the training period. The exercise intensity plays an important role in an effective functional fitness training process and should be adapted to individual elders' physical conditions accordingly. Exercise videogames by using technologies of motion detection or gesture recognition for elders' functional fitness training (e.g., fall prevention) become an acceptable, attractive, and sustainable approach among elders (Bieryla \& Dold, 2013; Bock et al., 2019; Ejupi, Gschwind, Valenzuela, Lord, \& Delbaere, 2016; Vaziri et al., 2017; Williams et al., 2010).

From the literature review, adaptive strategies with technology support are beneficial for elders' functional fitness training. However, the content of the training system is usually based on commercial exercise videogames instead of being specifically designed by functional fitness experts. The adjustment of exercise intensity levels (game difficulty) in those games is an adaptive strategy for the training, but it usually consider trainee's objective performance such as game scores (Bisio, Delfino, Lavagetto, \& Sciarrone, 2017; Bleser et al., 2015; Grewal et al., 2015). Trainees' feelings are usually overlooked in the training process with an adaptive strategy. Concurrently considering body-mind balance in an adaptive strategy for training is still in an embryonic stage. Hence, the aim of this study is to design and evaluate a dual adaptive strategy for adjusting exercise intensity levels in improving training efficiency of elders' functional fitness by using gesture recognition and perceived exertion. Two research questions are then proposed as follows: (1) What are the effects of the proposed strategy on the elders' training efficiency of functional fitness? (2) What are the effects of the proposed strategy on the elders' training experience of functional fitness?

\section{The dual adaptive strategy}

For reaching the research goal, this study must provide effective training content and a corresponding exercising system to support the elders with the dual adaptive strategy. During the training process, the exercise intensity levels need to be adjusted based on elders' physiological conditions and their needs. The exercising system is also required to provide the elders easy-to-use operations.

\section{The exercise intensity levels in a function fitness training system}

Elders start to face different health concerns as they age. As individuals start to grow old, insufficient regular exercise could easily lead to muscle mass decline, muscle reduction, stiff joints, and skeletal weakness. More importantly, the muscle mass of lower extremities declines faster than upper counterparts, and the muscle endurance of lower extremities plays a significant role in elders' daily movements, such as standing and walking, to maintain a normal life. Therefore, regular and continuous exercise is a common approach to improve the elders' functional fitness and mitigate the impacts of aging. Appropriate training for the elders is important and help the elders exercise efficiently during the process. Exercising systems were usually developed by objective assessments regarding trainees' physical conditions to adjust the content of training (Bisio et al., 2017; Bleser et al., 2015; Grewal et al., 2015). However, trainees' psychological status might affect the training and needs to be considered during the training process.

An exercise training process has been designed in this study, with the help of two physical fitness experts. Five types of movements are used as the functional fitness exercises in the training process (Table 1). After elders carry out and complete an exercise, they then 
Table 1 Five types of movements for improving the elders' functional fitness

Aype Name
A Standing side leg
raise

${ }^{a}$ Carried out for both right and left sides of lower extremities with two positions

conduct a self-reported measurement called the rate of perceived exertion (RPE), which is wildly used to measure exercise tolerance. The measured RPE data can inform the designers in terms of elders' perceptual data of sensations, including strain, aches, and fatigue. These data are used for determining suitable modalities for the next exercises (Borg, 1970, 1982; Groslambert \& Mahon, 2006; Zhao, Chung, \& Tong, 2017). By considering subjective feedback of RPE, the adjustment of training content can cover both present physical conditions and psychological status of the elders during the training process. Training efficiency then can be investigated if it has improvement. Therefore, the RPE is measured as the reference for adjusting the exercise intensity levels in the dual adaptive strategy. The scale of RPE ranges from 6 to 20, where " 6 " means "no exertion at all" and "20" means "maximal exertion." For the general public, the American Heart Association and related studies recommend moderate-intensity physical activity (RPE = 11 14) (American Heart Association, 2015; Tsai, Huang, Chen, \& Ting, 2015; Wewege, Thom, Rye, \& Parmenter, 2018). Based on the suggestions, two experts of functional fitness in this study developed a set of intensity levels (Table 2) for elders' training.

After determining the five types of movements and the set of intensity levels, whereby four out of the five movements consist of left and right positions, the dual adaptive strategy for adjusting exercise intensity levels is then designed for achieving a better bodymind balance during the training process. The main idea is to integrate objective 
Table $\mathbf{2}$ The set of intensity levels of the functional fitness training

\begin{tabular}{llll}
\hline Intensity level & $\begin{array}{l}\text { Time for remaining } \\
\text { movements (seconds) }\end{array}$ & Weight-bearing (lbs.) & Note \\
\hline 1 & 2 & 0 & n/a \\
2 & 4 & 0 & \\
3 & 6 & 0 & \\
4 & 8 & 0 & \\
5 & 10 & 0 & The weight for each extremity \\
6 & 12 & 0 & (all 4 extremities required) \\
7 & 12 & 1 & \\
8 & 12 & 2 & \\
9 & 12 & 3 & \\
10 & 12 & 4 & \\
11 & 12 & 5 &
\end{tabular}

n/a No available notes

assessments and subjective feedback into the adaptive design. To evaluate the idea, this study proposed two adaptive strategies for training.

In a training process, the most common objective assessments as a real-time performance index, movement correctness rate (MCR), is the conformity of participants' movements to the standard movements, which represents how well the participants perform the exercise. The judgment mechanism for the five types of movements for improving functional fitness. A specific gesture recognition feature is used to judge whether a correct movement has been made (see Fig. 1). For example, there are two key points of skeleton joints (i.e., A and C) for "standing side leg raise" when the elder was doing the movement with the right leg. If the distance between $\mathrm{A}$ and $\mathrm{C}$ points from $\mathrm{X}$-axis is greater than 0.4 and the distance between $\mathrm{A}$

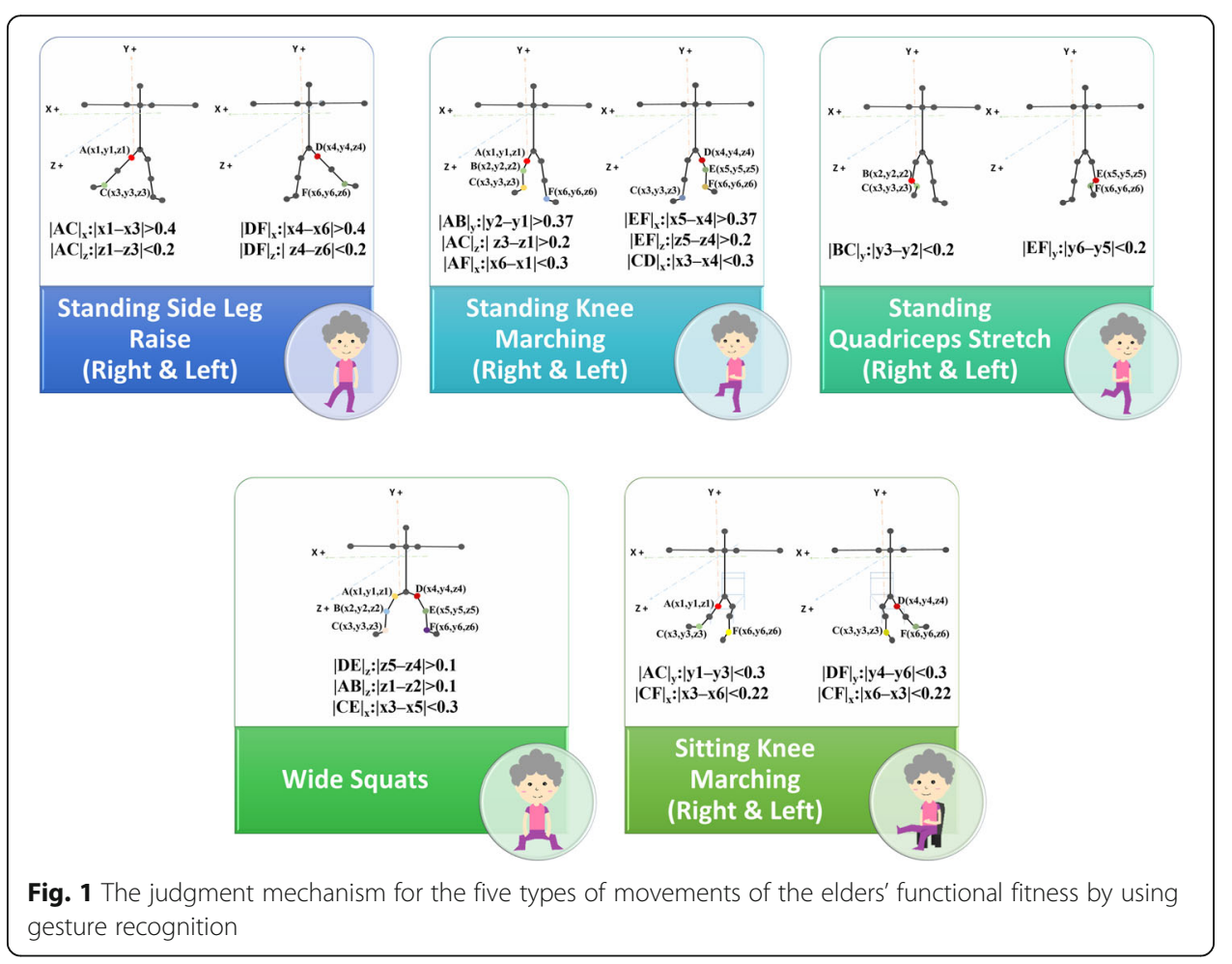


and $C$ points from Z-axis is less than 0.2 , the elder's current position of the movement is judged to be correct. Accordingly, the first strategy only takes MCR into consideration (see Fig. 2). The other strategy integrates MCR and the considerable subjective feedback (i.e., RPE) into the design during the exercise period (see Fig. 3). Then, these two strategies form the mechanisms to adjust the exercise intensity levels during the training process. For an exercise session, the participants need to do the training with several cycles, and each cycle consists of nine positions. Every position needs to be completed within $12 \mathrm{~s}$ because the experts suggest that the amount of time is enough to complete even the highest intensity level position. After every cycle is finished, the MCR is calculated to determine the exercise intensity levels for the next iteration. Table 3 presents the details of adjusting exercise intensity levels in this study. For the two adaptive strategies, the exercise intensity level in the next cycle increases when the participants' MCR is greater than 7/9 and decreases when the

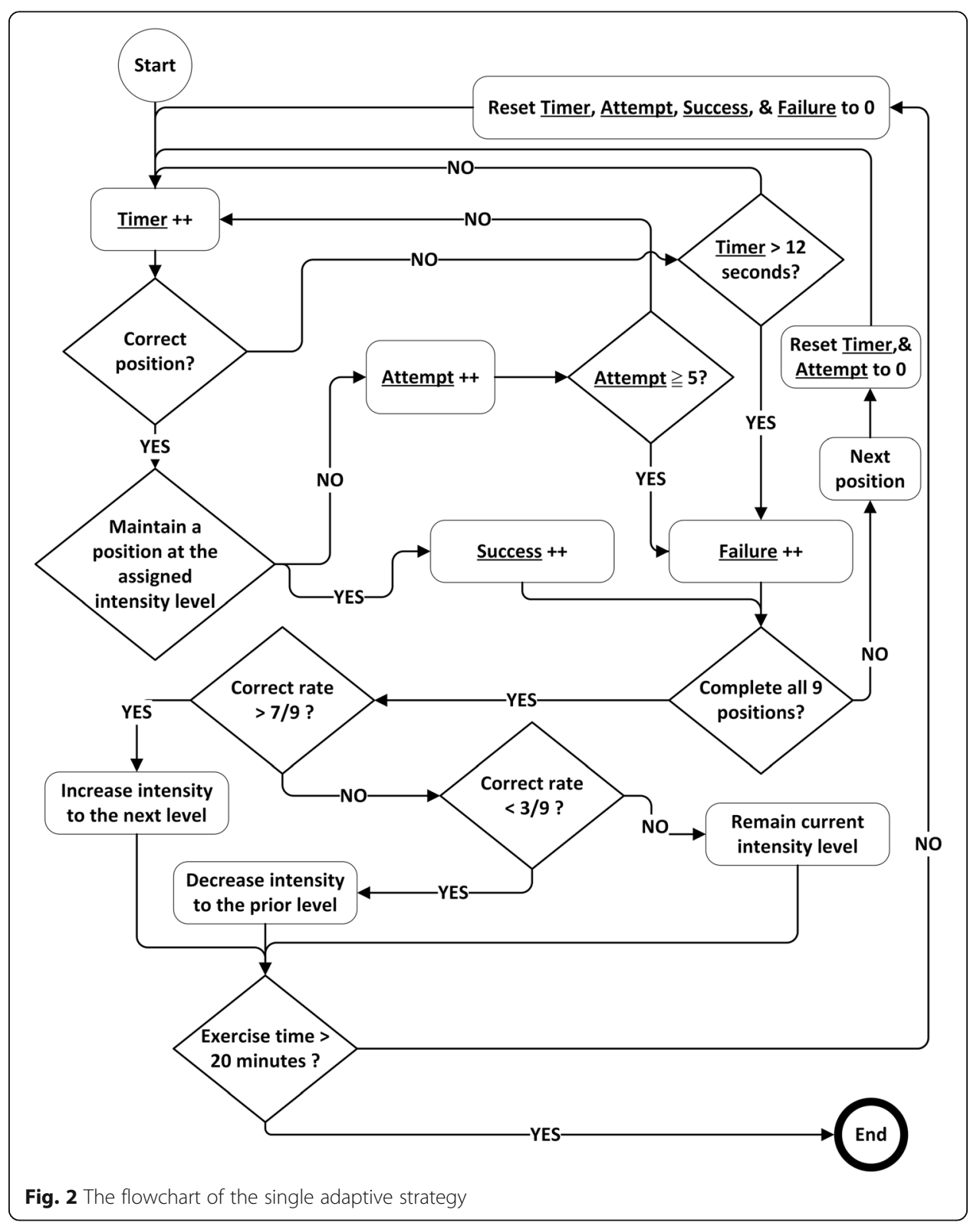




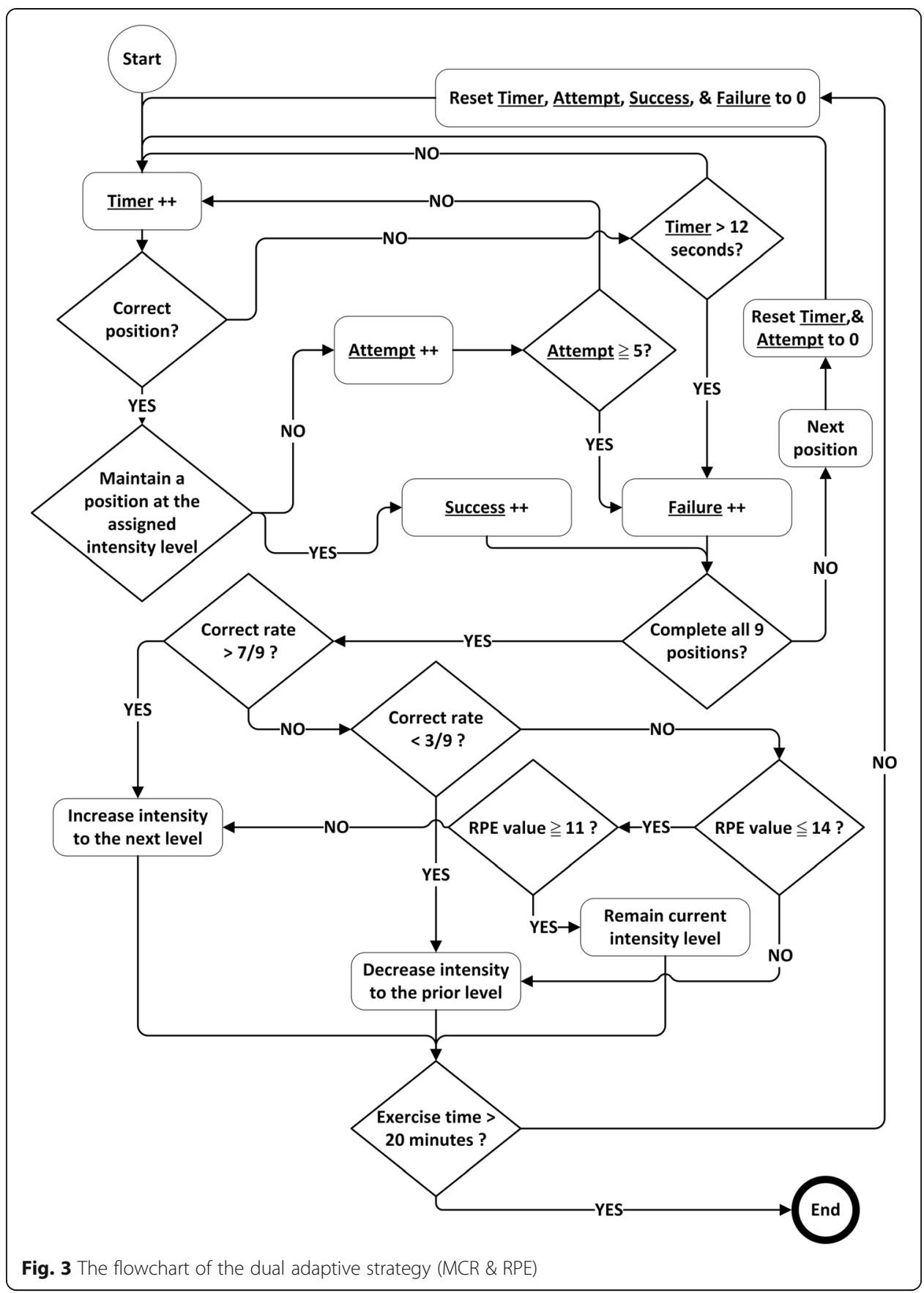

participants' MCR is less than 3/9. The difference between the two adaptive strategies is in the MCR interval from 3/9 to 7/9. For the single adaptive strategy, the next cycle remains the same exercise intensity level as the current cycle because of the MCR interval. The dual adaptive strategy makes further adjustments by referencing to RPE concurrently in the MCR interval. The exercise intensity level of the next cycle remains the same as the current cycle for the dual adaptive strategy when the MCR interval occurs and participants' RPE is in between 11 and 14. In addition to the MCR interval, the exercise intensity level in the next cycle increases when the participants' RPE is greater than 14 and decreases when the participants' RPE is less than 11 for the dual adaptive strategy. 
Table 3 The adaptive strategies for adjusting exercise intensity levels

\begin{tabular}{|c|c|c|}
\hline Intensity Adjustment & $\begin{array}{l}\text { Single adaptive strategy } \\
\text { (MCR) }\end{array}$ & $\begin{array}{l}\text { Dual adaptive strategy } \\
\text { (MCR \& RPE) }\end{array}$ \\
\hline Increase (Obj.) & $M C R>7 / 9$ & $M C R>7 / 9$ \\
\hline Decrease (Obj.) & $M C R<3 / 9$ & $M C R<3 / 9$ \\
\hline Remain (Obj.) & $3 / 9 \leqq M C R \leqq 7 / 9$ & - \\
\hline Increase (Subj.) & - & $3 / 9 \leqq M C R \leqq 7 / 9 \& r R P E<11$ \\
\hline Decrease (Subj.) & - & $3 / 9 \leqq M C R \leqq 7 / 9 \& r R P E>14$ \\
\hline Remain (Subj.) & - & $3 / 9 \leqq M C R \leqq 7 / 9 \& 11 \leqq r R P E \leqq 14$ \\
\hline
\end{tabular}

\section{Adaptive exercising system - EverGreen}

For evaluating the effects of the dual adaptive strategy for adjusting exercise intensity levels, an adaptive exercising system (i.e., EverGreen) has been used in this study by using Microsoft Kinect to provide the capability of sensing the elders' real-time movements. The EverGreen system was developed in previous studies (Sheu, Lee, Hsu, \& Chen, 2015; Sheu, Lee, Yang, \& Chen, 2015). Related operational logics and user interface of the EverGreen system was designed for elders to exercise in a safe, convenient, and enjoyable manner. The system can support the whole training process with the two adaptive strategies and help the elders do the training with appropriate audiovisual representation. Based on the suggestions provided by the two experts, the whole training schedule is designed for 8 weeks with a total of ten 30-min sessions.

Each session consists of three stages, namely warm-up, functional fitness, and cooldown exercises. First, a 5-min warm-up exercise is provided to the elders via a video instruction "Fall Prevention Exercise for The Elderly" (https://youtu.be/wZaNWpxGAYc) prepared by Taiwan's Department of Health. The main purpose is to prepare the elders' bodies steadily and safely at the beginning of the exercise session for the successive physical activities of functional fitness by gradually increasing the heart rate and blood circulation. Moreover, the warm-up session is very important to prevent acute injury during exercises.

After completing the warm-up stage, the elderly would move towards the functional fitness stage that encompasses a total of nine positions, based on the five types of movements, to train the endurance of lower extremities. During this stage, elders have $20 \mathrm{~min}$ to perform the functional fitness exercise with a repeated cycle including the nine positions and a maximum of five attempts for each position. If the elders cannot complete an assigned position within five attempts, the system will switch to other positions automatically. For the dual adaptive strategy, the rate of perceived exertion (RPE) measurement (see Fig. 4) will be used to adjust the intensity level of exercise based on the elders' inputs when the movement correctness rate (MCR) is between 3/9 and $7 / 9$ at the end of each cycle.

Finally, the session ends with a 5-min cooldown exercise which is composed of seven positions, as suggested by the two physical fitness experts (Table 4). Such light exercises can assist in the transition of gradually relaxing the body after intense exercises, which are beneficial for reducing strain muscles, preventing dizziness and discomfort of the lower extremities, and promoting a better feeling after the workout. The cooldown exercise is not highly related to the functional fitness of lower extremities because its main purpose is to help the body recover back to its normal state. 


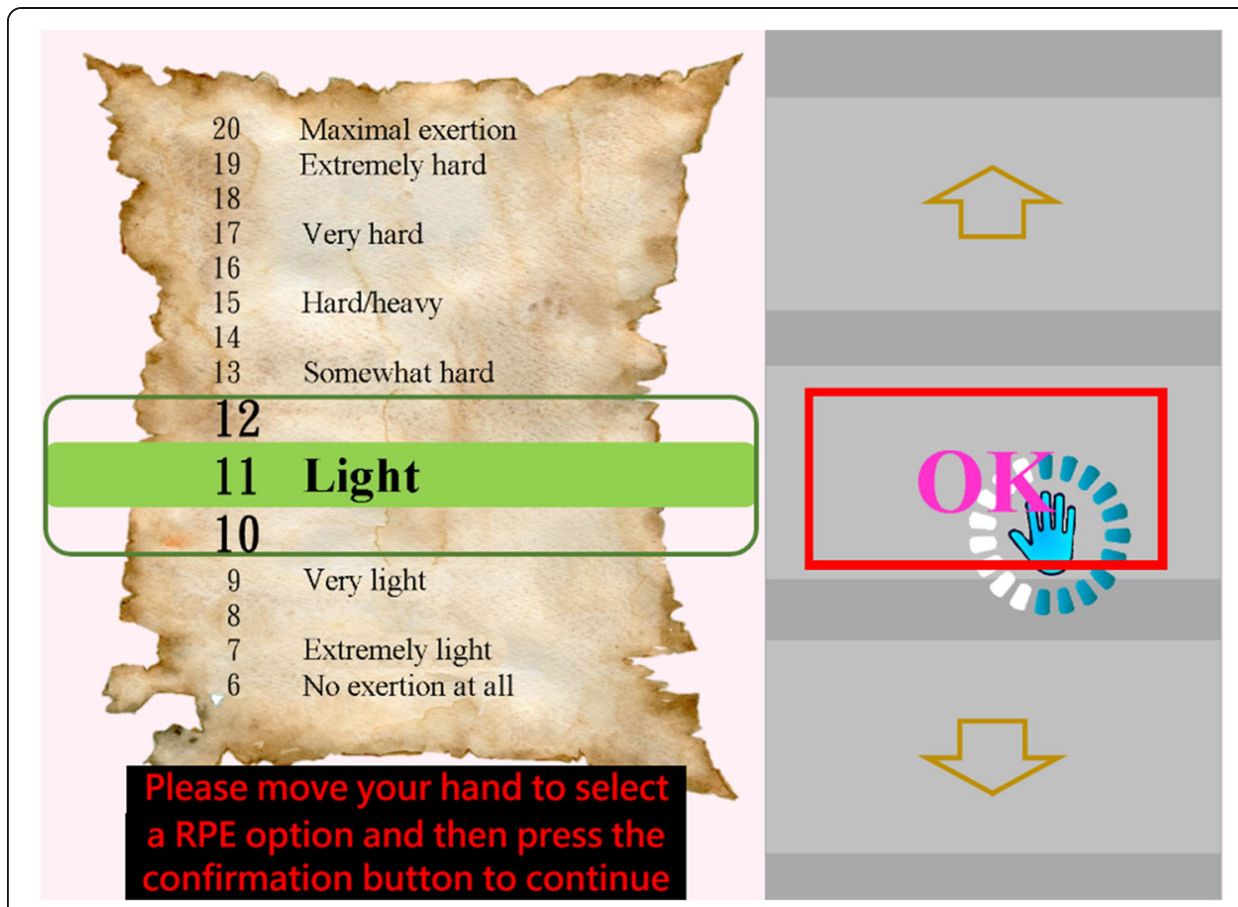

Fig. 4 The screenshot of selecting an RPE option based on Borg (1982)

Since the human physiological functions gradually degrade in normal human aging, the use of new technologies is more difficult for elders compared to young people, they require simple user interfaces to overcome various operational obstacles (Fisk, Rogers, Charness, Czaja, \& Sharit, 2009). Therefore, EverGreen system adopted the motionsensing technology to provide the elders a simple and intuitive user interface by recognizing human gestures. Only one important object will show up on screen at a time throughout the whole system operation process. Regarding the system menu, the "hand cursor" provides a linkage to the right hand's motions of the elders in real time so that they can directly use their movements of the right hand to select an option. Holding the position of the hand cursor for $3 \mathrm{~s}$ triggers a positive confirmation of the elders' inputs or feedback toward the system (see Figs. 5 and 6).

During the functional fitness exercise, the EverGreen system detects every motions of the elders and gives them appropriate feedback. For example, the text feedback "detecting" shows up on the display when the elders are trying to complete the assigned position. When the elders are maintaining the assigned position, a countdown begins in the unit of seconds based on the current intensity level (see Fig. 7). At the same time, the video feedback also changes in real time so that the elders can tell if their actual motions are consistent with the virtual coach on screen.

\section{Experimental design}

\section{Participants}

According to World Health Organization, individuals who are 65 years old and above are regarded as the elderly. Although the current statutory retirement age in 
Table 4 Seven positions of the cooldown exercise

\begin{tabular}{llll}
\hline No. & Name & Walking on the spot \\
\hline 1 & &
\end{tabular}
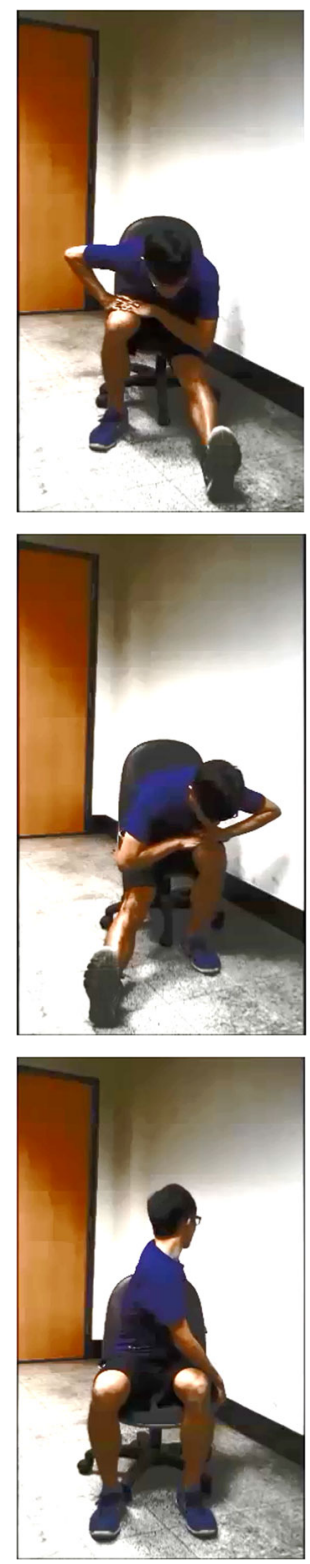
Table 4 Seven positions of the cooldown exercise (Continued)

No. Name Position
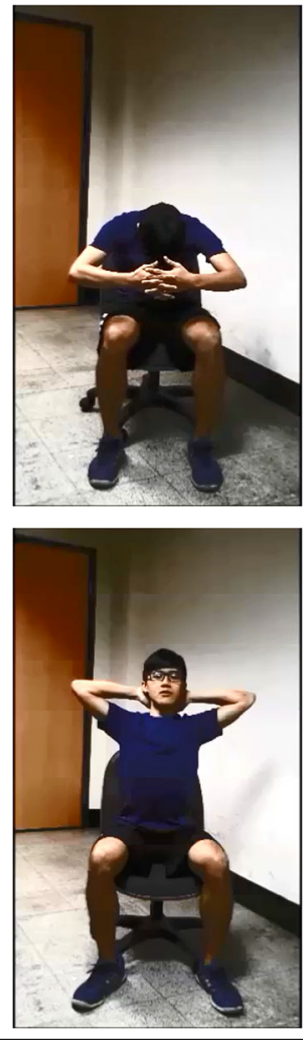

Taiwan is also 65 years old, the actual average retirement age is about 57 years old (Directorate General of Budget Accounting, and Statistics, R. O. C, 2013). After the retirement, the physical conditions of the elders degrade rapidly due to the absence of work or the lack of exercises. If the elders can develop good exercise habits, they can take the opportunity to maintain their health in the early stage of the degrading period. Therefore, the target participants of this study are elders between the ages of 57 80 in Taiwan who are capable of self-activity and possess self-care ability with no potential health risk in doing exercises. A total of 30 participants were finally considered as valid samples in this experiment from two universities for sensors. They were randomly and equally assigned to the two groups of this experiment. 


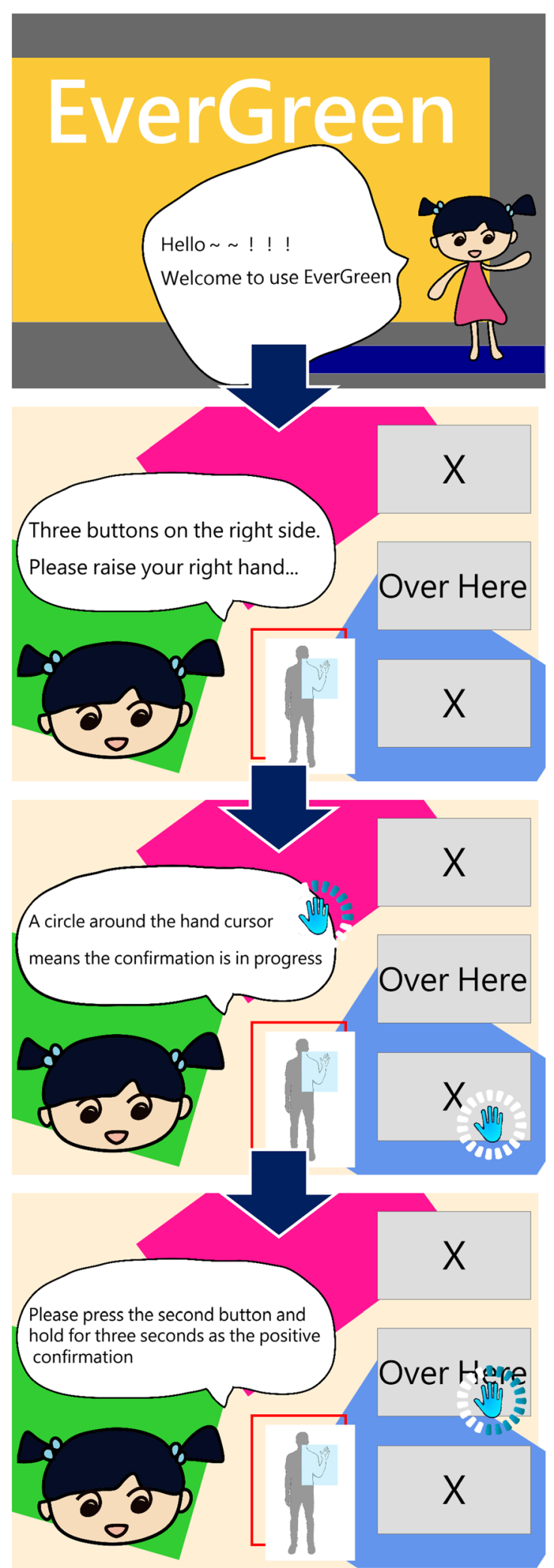

Fig. 5 The operational instruction of the hand cursor in the EverGreen system 


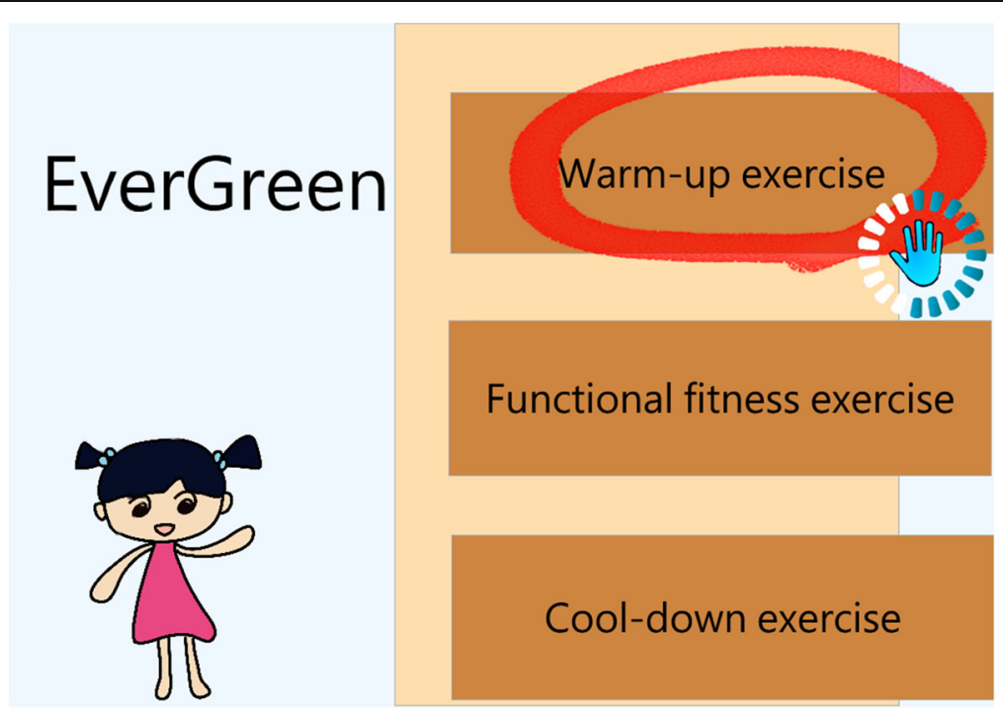

Fig. 6 The main menu of the EverGreen system

\section{Instruments}

In order to understand the elders training efficiency of functional fitness, this study analyzed the changes and trend of participants' exercise intensity levels during the training sessions. The exercise intensity levels which are not too easy or too hard for the participants can be considered an appropriate training. Besides, this study used the senior fitness test (SFT) to examine the effectiveness of the training content and the exercising system. The SFT was proposed by Rikli and Jones (1999) to assess the elders' ability to perform physical activity in their daily life. The entire test procedure was conducted by a certified specialist. The SFT consists of upper and lower extremities endurance, shoulder and lower extremities softness, cardiorespiratory endurance, agility, and dynamic balance. Only the test item for lower extremities was used because the purpose of the adaptive exercising system was for lower extremities in this study.

Although the dual adaptive strategy was carefully designed and introduced to the elders, the improvement of functional fitness training performance depends on their regular and continuous exercise in the daily life. Thus, the elders' satisfaction accordingly would affect their intention to continue using EverGreen in the future. This study adopted the measurement of satisfaction proposed by Chiu, Hsu, Sun, Lin, and Sun (2005) to

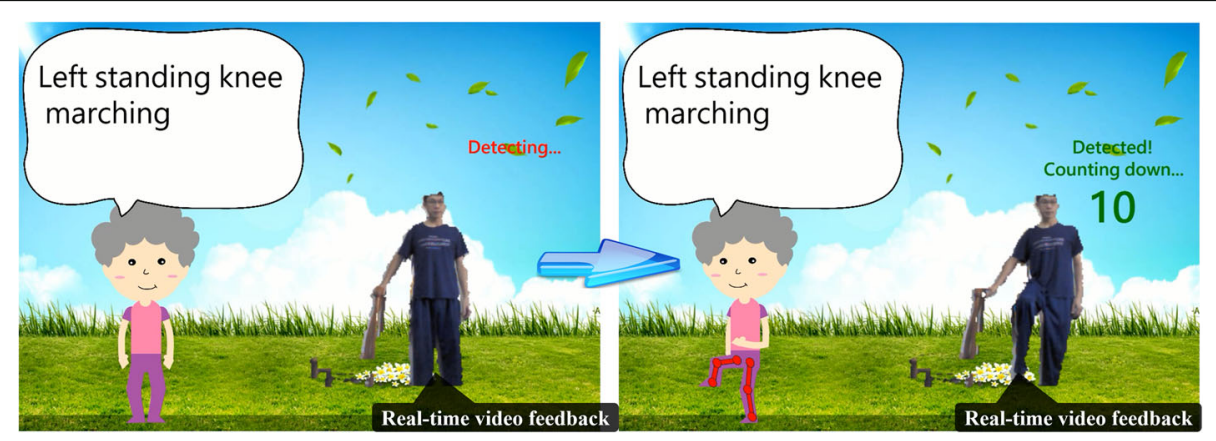

Fig. 7 The real-time feedback given by EverGreen system 
understand the elders' satisfaction toward the adaptive exercising system. The measurement of satisfaction consisted of three question items with the 5-point Likert scale ( 1 = strongly disagree and $5=$ strongly agree $)$.

During the exercise, the new approach was applied to the training process in this study. In order to understand how well the elders engage in the training, this study adopted the measurement of EGameFlow proposed by $\mathrm{Fu}, \mathrm{Su}$, and $\mathrm{Yu}$ (2009). The measurement of EGameFlow is composed of concentration, goal clarity, feedback, challenge, autonomy, immersion, and social interaction. Because the social interaction was not included in the research scope and design, only the first seven constructs were used to assess the elders' flow state. A total of 34 question items were used with the 5-point Likert scale $(1=$ strongly disagree and $5=$ strongly agree $)$.

\section{Adaptive exercising system - EverGreen}

An experiment with two groups was created to investigate the effects of the dual adaptive strategy on the elders' functional fitness with the embodiment exercising training system. Thirty elders were recruited for this experiment. They were assigned to either group A or group B randomly and equally. The experimental procedure is shown in Fig. 8. The group A adopted the single adaptive strategy (i.e., MCR), and the group B was with the dual adaptive strategy (i.e., MCR \& RPE). All participants were asked to maintain their usual lifestyles except the functional fitness interventions. In the first session with the participants, a 15-min introduction regarding this experiment and the system operations was given to all participants. After that, all participants took the SFT for $20 \mathrm{~min}$ as the pre-test. The testing process was performed by a functional fitness specialist with official practice licenses to ensure the participants' safety and the accuracy of the data.

After the pre-test session, a total of 10 activity sessions were conducted in 8 weeks. The hardware of the adaptive exercising system and the experimental environment are shown in Figs. 9 and 10 respectively. During the 30-min activity sessions, the participants in group A and group B started with the 5-min warm-up exercise to well prepare

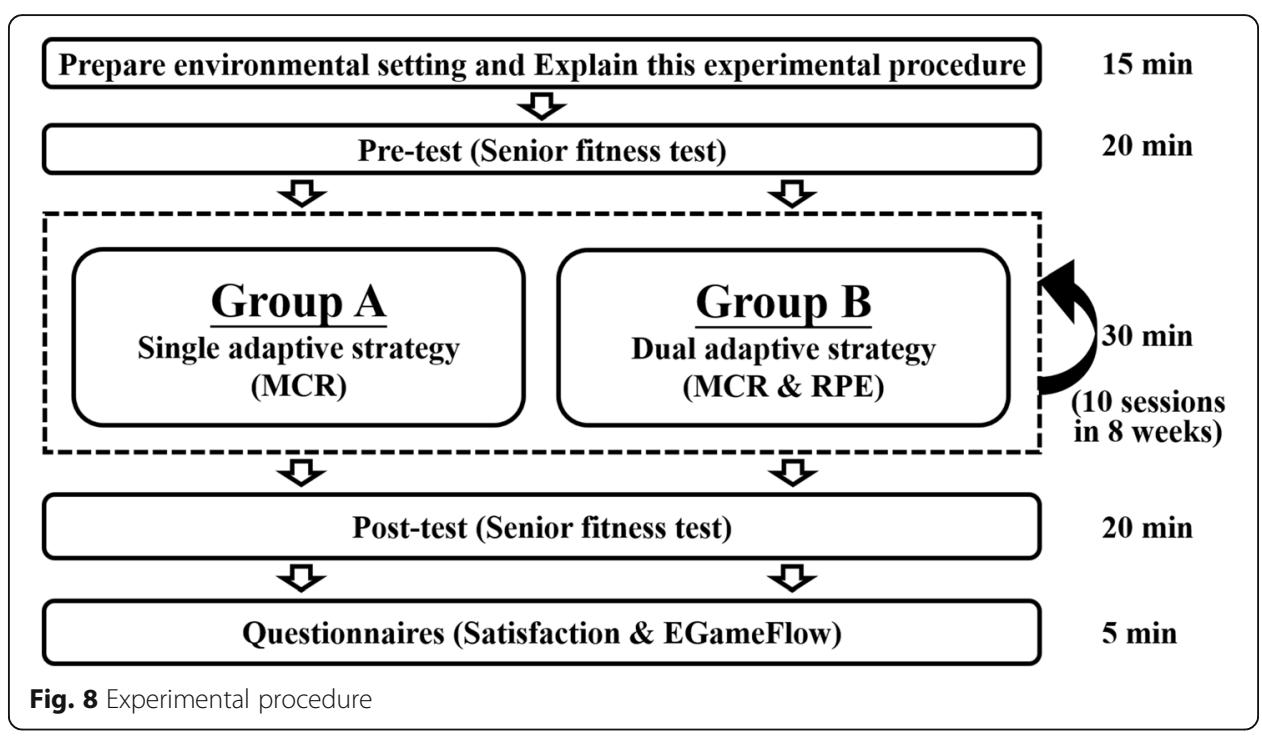




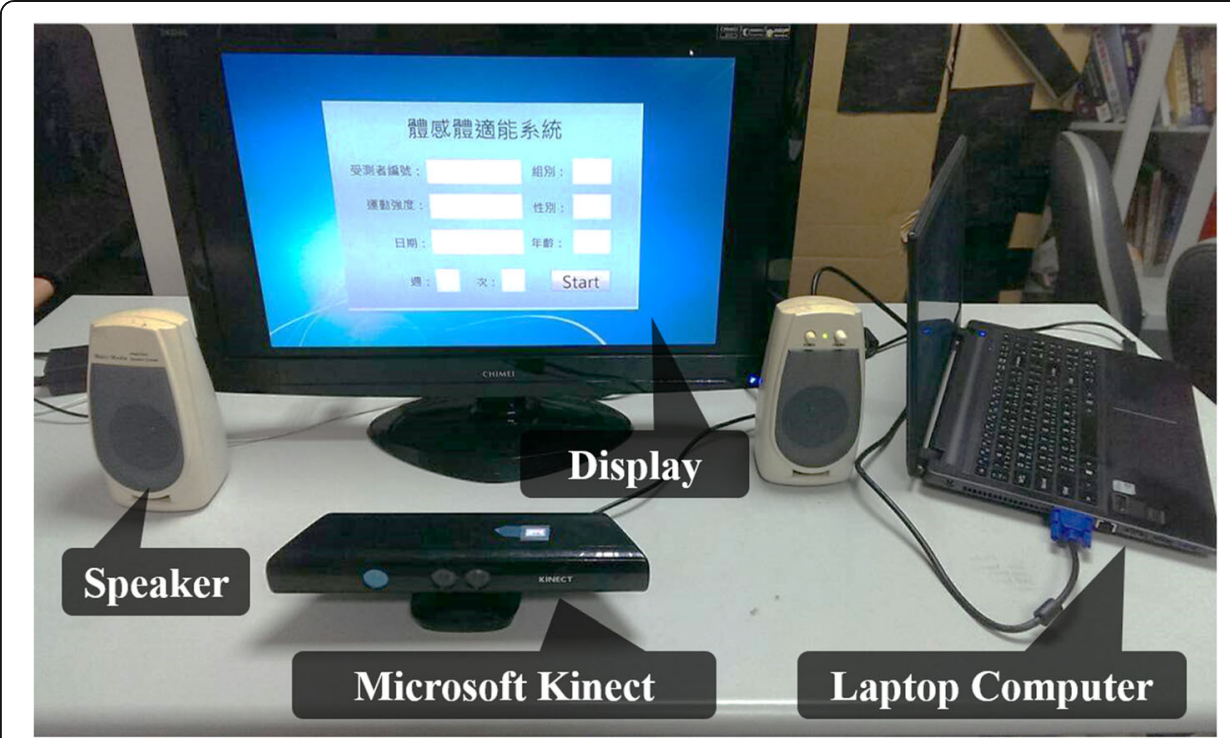

Fig. 9 The hardware of the adaptive exercising system

themselves to carry out the successive functional fitness exercise (see Fig. 11). Then, the functional fitness exercise was performed with the dual adaptive strategy. The participants in group A and group B were required to complete a total of nine positions in a cycle, and they continually repeated the cycle for $20 \mathrm{~min}$ (see Fig. 12). The exercise intensity level changes or remains in the next cycle in accordance with the dual adaptive strategy in group A and group B. When the movement correctness rate is greater than $7 / 9$ or less than $3 / 9$ at the end of each cycle, the system for the group A then increase or decrease the exercise intensity level in the next cycle. The intensity level remains without any changes in the next cycle for the group $\mathrm{A}$ as the movement correctness rate is in between 3/9 and 7/9; the participants in group B make subjective responses with the RPE values to determine the intensity level of the next cycle. After

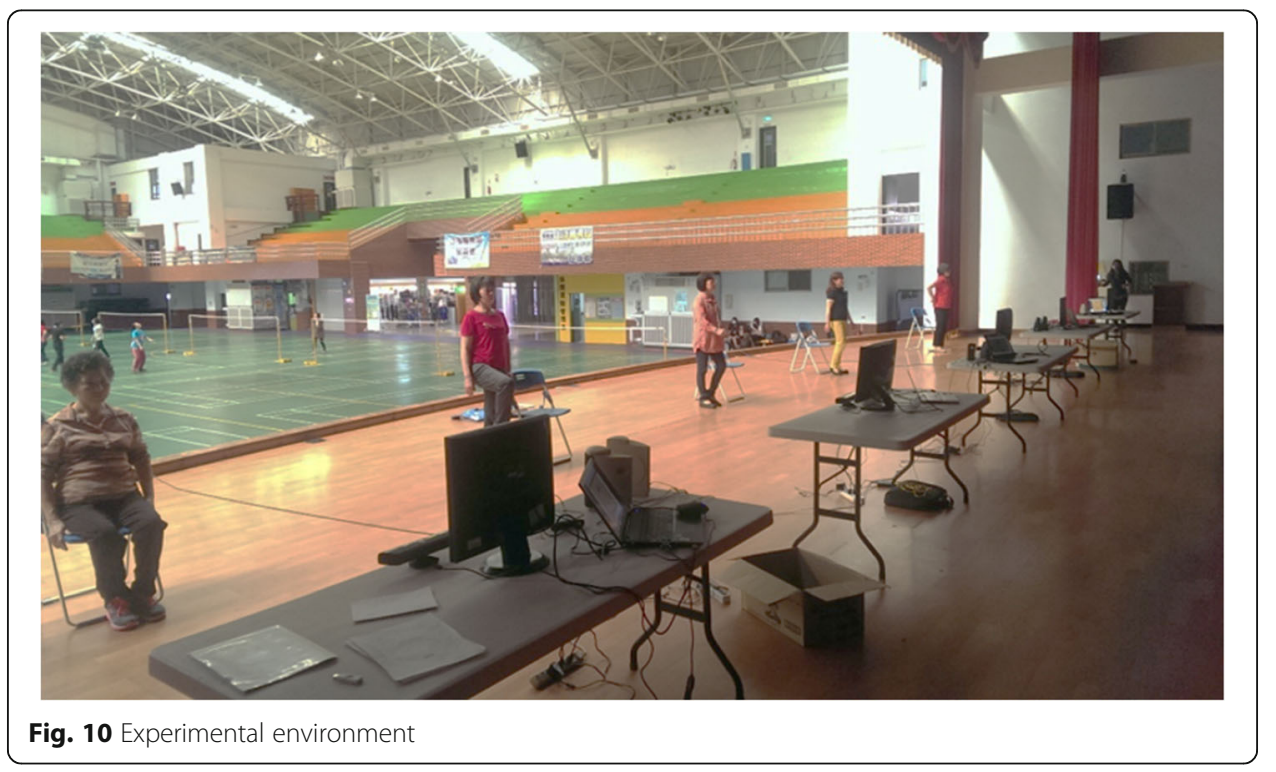




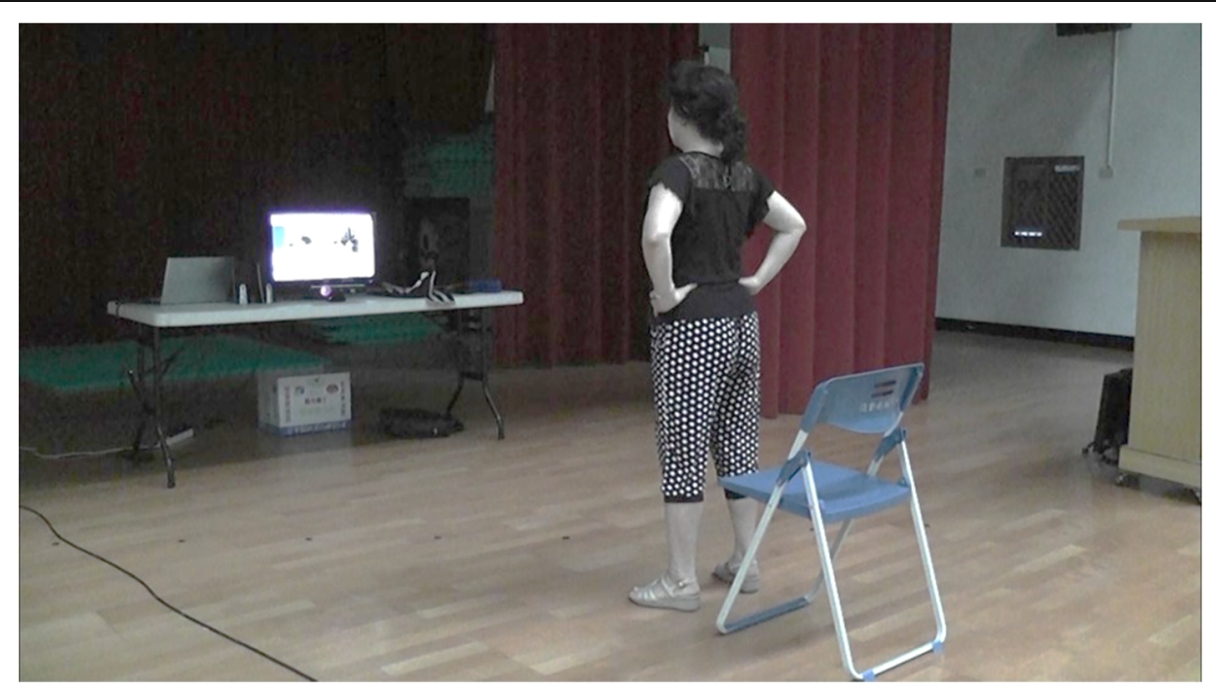

Fig. 11 Executing the warm-up exercise

the 20-min functional fitness exercise, the participants in group A and group B continued to perform a 5-min cooldown exercise (see Fig. 13).

After the 10 sessions, all participants completed the same SFT in $20 \mathrm{~min}$ as the posttest. Participants in group A and group B additionally filled out a questionnaire in 5 min, assessing their satisfaction and engagement in their usage experience of the system.

\section{Results}

The participants in this study were recruited from two senior citizens learning camps in Tainan and Kaohsiung, two cities in Taiwan. The average age was 65.03 years old, and 28 out of the participants were female. An 8-week experiment with 10 sessions was conducted to evaluate the effects of the dual adaptive strategy on training efficiency and training experience of functional fitness. The next step was to analyze the pre-test,

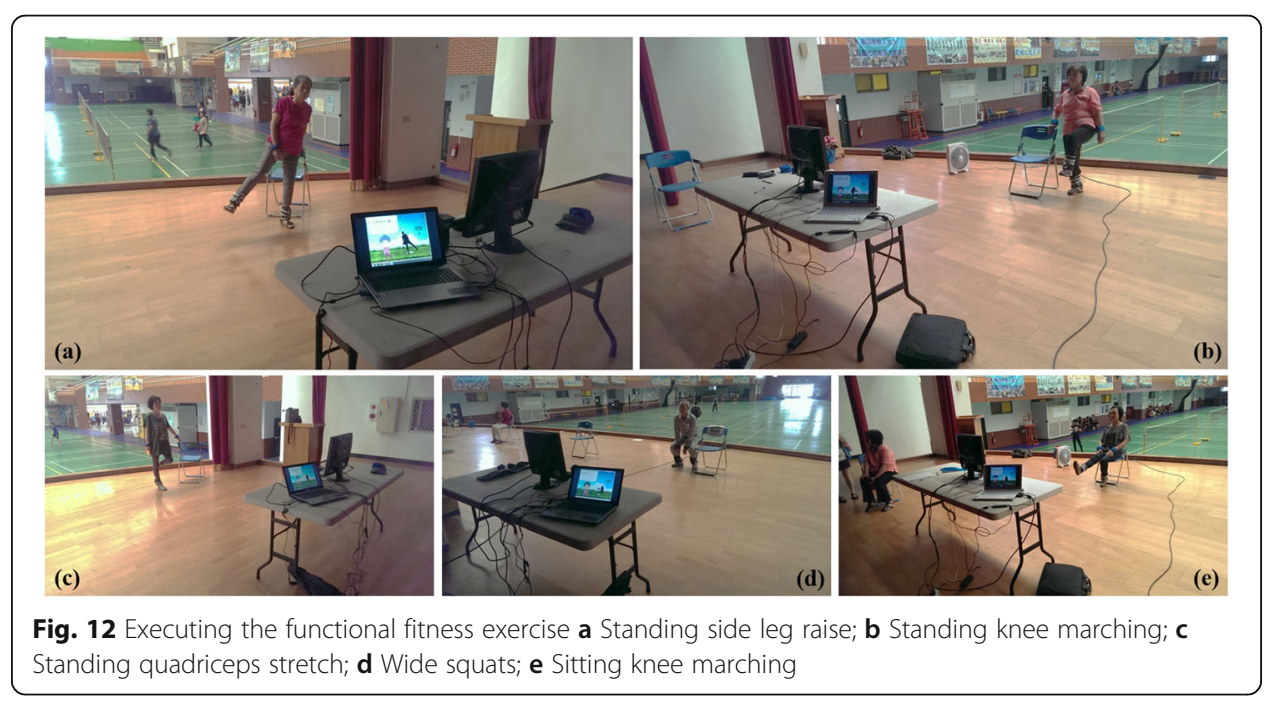




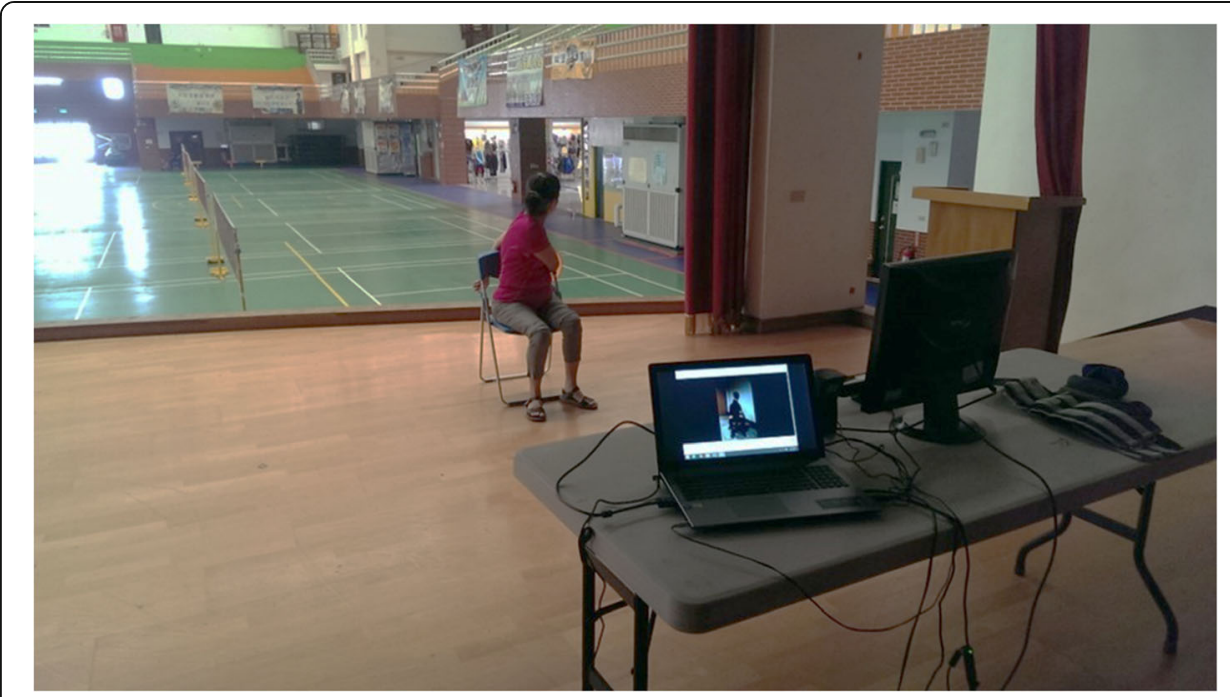

Fig. 13 Executing the cooldown exercise

the post-test, exercise intensity levels, the satisfaction questionnaire, and the EGameFlow questionnaire. Each group had 15 valid samples for the subsequent analyses.

\section{Analysis of lower extremity functional fitness training efficiency}

First, the effectiveness of the training content and the exercising system need be confirmed for the elders' functional fitness. The within-group and between-group t-tests of SFT outcomes including gain scores (post-test - pre-test) were performed (Tables 5 and 6). The within-group results show that the participants in the group A $(t=-3.18, p=0.007<0.01$, Cohen's $d=0.78)$ and the group B $(t=-2.72, p=0.017<0.05$, Cohen's $d=0.87)$ had improvement of training performance in their lower extremity functional fitness after training. The training content and the exercising system can help the elders improved their lower extremity functional fitness. In terms of the between-group results, no significant differences were found when comparing the group A with the group B. During the short-term period in this study, the improvement of training performance in the elders' function fitness did not accumulate significant difference yet between the two adaptive strategies.

All participants had the training from the level 1 of exercise intensity at the beginning of this experiment. In order to analyze the elders' training efficiency of functional fitness, the changes were plotted with corresponding linear trend lines (see Fig. 14). The repeated measure ANOVA was used for the analysis. Huynh-Feldt corrections were applied for any significant violations of sphericity and original degrees of freedom with adjusted $p$ values are reported in Table 7. The interaction between session and group is

Table 5 The within-group result of t-test in the SFT scores

\begin{tabular}{|c|c|c|c|c|c|c|c|c|}
\hline \multirow[t]{2}{*}{ Group } & \multicolumn{3}{|c|}{ Pre-test } & \multicolumn{3}{|c|}{ Post-test } & \multirow[t]{2}{*}{$t(p)$} & \multirow{2}{*}{$\begin{array}{l}\text { Cohen's } \\
d\end{array}$} \\
\hline & $\overline{\mathrm{N}}$ & Mean & S.D. & $\bar{N}$ & Mean & S.D. & & \\
\hline A & 15 & 69.83 & 27.49 & 15 & 87.00 & 14.37 & $-3.18\left(0.007^{* *}\right)$ & 0.78 \\
\hline B & 15 & 72.67 & 25.20 & 15 & 90.33 & 13.43 & $-2.72\left(0.017^{*}\right)$ & 0.87 \\
\hline
\end{tabular}


Table 6 The between-group result of t-test in the SFT scores

\begin{tabular}{llllll}
\hline Variable & Group & N & Mean & S.D. & $t(p)$ \\
\hline Pre-test & A & 15 & 69.83 & 27.49 & $-0.29(0.771)$ \\
& B & 15 & 72.67 & 25.20 & \\
Post-test & A & 15 & 87.00 & 14.37 & $-0.66(0.517)$ \\
& B & 15 & 90.33 & 13.43 & \\
Gain (Post-test - Pre-test) & A & 15 & 17.17 & 20.93 & $-0.06(0.953)$ \\
& B & 15 & 17.67 & 25.20 & \\
\hline
\end{tabular}

significant $(F=2.54 ; p=0.046<0.05)$. The differences in each session between group A and group B were the purpose of this study. The follow-up ANOVA for each session was conducted to understand the difference of the intensity level between group A and group B (simple main effects). As shown in Table 8, the result shows that significant differences of exercise intensity levels between group A and group B were found from the 3rd $(F=4.39, p=0.045<0.05$, partial eta squared $=0.135)$ to the 10 th $(F=5.72, p=$ $0.024<0.05$, partial eta squared $=0.170$ ) sessions. The dual adaptive strategy meets the trainees' needs of skill formation more quickly than the single adaptive strategy for appropriate training.

\section{Analysis of training experience}

The construct of satisfaction presented high reliability (Cronbach's $\alpha=0.968)$. The data of satisfaction was analyzed by independent samples $t$-test. As shown in Table 9 , the means were 4.44 for group A and 4.40 for group B although the $t$-test result shows that no significant difference was found on the construct of satisfaction $(t=0.25, p=0.808)$.

The EGameFlow questionnaire developed by $\mathrm{Fu}$ et al. (2009) was used to investigate the differences of flow between the two groups when training with the adaptive exercising system. The 7 constructs presented high reliability and the results of $t$-test are show

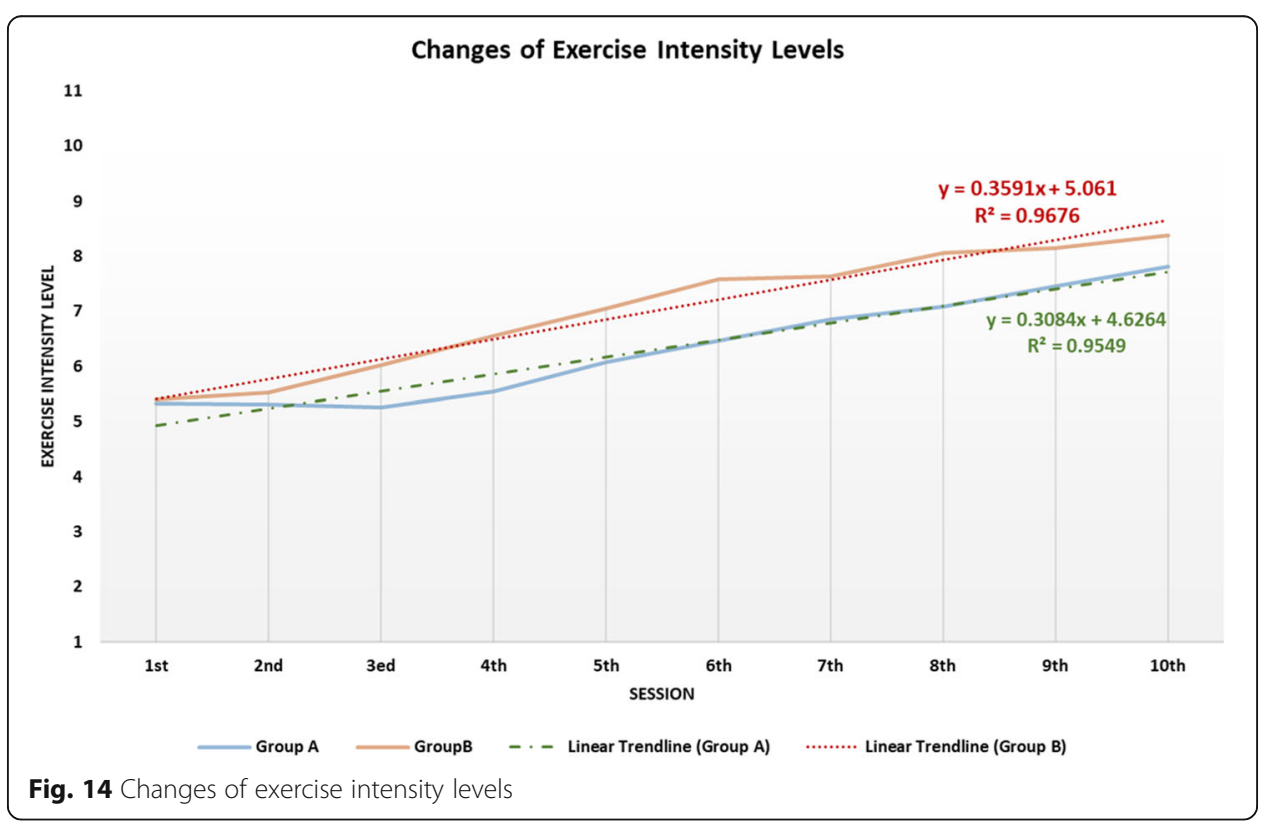


Table 7 The result of repeated measure ANOVA in the intensity level of the 10 sessions

\begin{tabular}{llllllc}
\hline Source & SS & df & MS & $F$ & $P$ & Partial Eta Squared \\
\hline Session & 280.27 & 3.99 & 70.28 & $88.68^{* * *}$ & 0.000 & 0.760 \\
Session * Group & 7.94 & 3.99 & 1.99 & $2.51^{*}$ & 0.046 & 0.082 \\
Error (Session) & 88.50 & 111.66 & 0.79 & & & \\
\hline
\end{tabular}

${ }^{*} p<0.05,{ }^{* * *} p<0.001$

in Table 10. In terms of concentration $(t=2.71, p=0.011<0.05$, Cohen's $d=0.99)$ and immersion $(t=2.88, p=0.008<0.001$, Cohen's $d=1.04)$, the scores of the group A are significantly higher than that of the group $B$.

\section{Discussion}

\section{Training efficiency of lower extremity functional fitness}

Literature has suggested that gradually adjusting exercise intensity levels based on the elders' physical conditions during the exercise period is the key design principle of training (Pruitt, 2003). According to the SFT results, the training content and exercising system demonstrate the effectiveness for improving all participants' lower extremity functional fitness after the 10 training sessions. The between-group result indicates that the elders with the dual adaptive strategy did not have better or worse lower extremity functional fitness than the elders with the single adaptive strategy before the study. On the other hand, the dual adaptive strategy can adjust the intensity level to align with

Table 8 The result of ANOVA in the intensity level of each session

\begin{tabular}{|c|c|c|c|c|c|c|c|}
\hline Session & G & $\mathrm{N}$ & Mean & S.D. & $F$ & $P$ & Partial eta squared \\
\hline \multirow[t]{2}{*}{$1 \mathrm{st}$} & $A$ & 15 & 5.33 & 0.82 & 0.07 & 0.790 & - \\
\hline & B & 15 & 5.40 & 0.51 & & & \\
\hline \multirow[t]{2}{*}{ 2nd } & A & 15 & 5.31 & 0.80 & 0.61 & 0.442 & - \\
\hline & B & 15 & 5.53 & 0.78 & & & \\
\hline \multirow[t]{2}{*}{$3 r d$} & A & 15 & 5.27 & 0.98 & 4.39 & $0.045^{*}$ & 0.76 \\
\hline & B & 15 & 6.02 & 0.97 & & & \\
\hline \multirow[t]{2}{*}{ 4th } & A & 15 & 5.54 & 1.03 & 8.73 & $0.006^{* *}$ & 1.08 \\
\hline & $B$ & 15 & 6.55 & 0.84 & & & \\
\hline \multirow[t]{2}{*}{5 th } & $A$ & 15 & 6.08 & 0.91 & 9.88 & $0.004^{* *}$ & 1.15 \\
\hline & B & 15 & 7.04 & 0.75 & & & \\
\hline \multirow[t]{2}{*}{ 6th } & $A$ & 15 & 6.46 & 0.76 & 18.60 & $0.000^{* * *}$ & 1.57 \\
\hline & B & 15 & 7.58 & 0.65 & & & \\
\hline \multirow[t]{2}{*}{ 7th } & $A$ & 15 & 6.85 & 0.72 & 10.18 & $0.003^{* *}$ & 1.16 \\
\hline & B & 15 & 7.63 & 0.61 & & & \\
\hline \multirow[t]{2}{*}{ 8th } & $A$ & 15 & 7.10 & 0.80 & 12.34 & $0.002^{* *}$ & 1.28 \\
\hline & B & 15 & 8.07 & 0.72 & & & \\
\hline \multirow[t]{2}{*}{ 9th } & $A$ & 15 & 7.47 & 0.48 & 11.12 & $0.002^{* *}$ & 1.22 \\
\hline & B & 15 & 8.15 & 0.63 & & & \\
\hline \multirow[t]{2}{*}{ 10th } & $A$ & 15 & 7.81 & 0.67 & 5.72 & $0.024^{*}$ & 0.87 \\
\hline & B & 15 & 8.39 & 0.65 & & & \\
\hline
\end{tabular}

$G$ Group

${ }^{*} p<0.05,{ }^{* *} p<0.01,{ }^{* * *} p<0.001$ 
Table 9 The result of t-test in satisfaction

\begin{tabular}{lllllll}
\hline Construct & Group & N & Mean & S.D. & $t$ & $P$ \\
\hline Satisfaction & A & 15 & 4.44 & 0.48 & 0.25 & 0.808 \\
& B & 15 & 4.40 & 0.51 & & \\
\hline
\end{tabular}

the elders' physical conditions more quickly than the single adaptive strategy during the training process which suggests better training efficiency (Fig. 13). In Table 7, the exercise intensity level of the dual adaptive strategy was significantly higher than the single adaptive strategy in the 3rd to the 10th sessions. The exercise intensity differences between the two strategies were increasing in the first 6 sessions and then decreasing in the last 4 sessions. During the first 6 sessions, the dual adaptive strategy adjusted exercise intensity levels more efficiently to align with the participants' training needs than the single adaptive strategy, but this effect was petering during the successive 4 sessions. The maximum difference of the intensity levels between the two adaptive strategies occurred in the 6th session. In other words, the differences increased from the 3rd to the 6th sessions and then decreased from the 6th to the 10th sessions. Such changes are rational because the exercise intensity levels were approaching the elders' tolerance. The dual adaptive strategy tailors a more efficient and suitable adjustment of exercise intensity levels to the participants than the single adaptive strategy does because it considers objective assessments and subjective feedback during the training.

For future studies, the extent of motivation should be taken into consideration because it is related to elders' willpower to keep improving functional fitness within a high but effective exercise intensity level. From the longitudinal perspective, regular and continuous exercise can improve human physical conditions (Heywood et al., 2017). However, the result between the two adaptive strategies did not demonstrate significant improvement of training performance in the elders' function fitness yet. The possibile reason might be training period not long enough in this study. Since the dual

Table $\mathbf{1 0}$ The result of t-test in the EGameFlow

\begin{tabular}{lcccccccc}
\hline Construct & Cronbach's a & G & N & $M$ & S.D. & $t$ & $p$ & Cohen's $d$ \\
\hline Concentration & 0.927 & A & 15 & 4.69 & 0.41 & 2.71 & $0.011^{*}$ & 0.99 \\
& & B & 15 & 4.27 & 0.44 & & & \\
Goal Clarity & 0.943 & A & 15 & 4.45 & 0.50 & 1.16 & 0.256 & - \\
& & B & 15 & 4.30 & 0.40 & & & \\
Feedback & 0.941 & A & 15 & 4.52 & 0.49 & 1.93 & 0.064 & - \\
& & B & 15 & 4.17 & 0.49 & & & \\
Challenge & 0.919 & A & 15 & 4.63 & 0.42 & 1.95 & 0.062 & - \\
& & B & 15 & 4.20 & 0.45 & & & \\
Autonomy & 0.873 & A & 15 & 4.53 & 0.45 & 1.85 & 0.075 & - \\
& & B & 15 & 4.20 & 0.53 & & & \\
Immersion & 0.960 & A & 15 & 4.55 & 0.44 & 2.88 & $0.008^{* *}$ & 1.04 \\
Knowledge Improvement & 0.957 & A & 15 & 4.53 & 0.49 & 1.87 & 0.072 & - \\
& & B & 15 & 4.23 & 0.40 & & & \\
\hline
\end{tabular}

$G$ Group, $M$ Mean

${ }^{*} p<0.05,{ }^{* *} p<0.01,{ }^{* * *} p<0.001$ 
adaptive strategy can improve the training efficiency of function fitness, changing exercise environment benefiting the training performance could be another future design such as aquatic space to increase the modality of exercise intensity besides weight loading objects. Except for extending the training period, another suggestion to improve the dual adaptive strategy is a more precise and delicate adjustment of exercise intensity levels by utilizing objective assessments and subjective feedback with a weighted mechanism. Then, the dual adaptive strategy would help the elders maximize their training efficiency and promote the training performance within a reasonable training period.

\section{Training experience of lower extremity functional fitness}

According to the result of satisfaction, no significant difference was found between the two adaptive strategies for training. However, the mean values of satisfaction of the single and dual adaptive strategies are 4.44 and 4.40 respectively with the maximum value of 5. Such result indicates that the participants of both adaptive strategies were satisfied with the training experience after using the adaptive exercising system, and this system is helpful for motivating the elders to use it continually. The interaction design of the adaptive exercising system was based on the suggestions from literature, such as simple operations, intuitive user interface, and unified user experience so that the participants' satisfaction could be maintained at a high level (Bouwhuis, 2003; Fang, Sheu, Lin, Lee, \& Chen, 2015; Haigh, 1993). Furthermore, this study also conveyed the importance and the meaning of all activities during the training period to the participants, so that they would understand how each position would be beneficial to them. By comparing the SFT scores in the pre- and post-tests, the elders could obtain concrete evidence and understand the benefits of improving their health when performing the functional fitness exercises. As a result, the confidence of the elders engaged in this training could be enhanced and became a source of generating satisfaction when using the adaptive exercising system. This outcome was also consistent with the previous study conducted by Resnick and Spellbring (2000). As high usage satisfaction would result in the increase of intention to use the adaptive exercising system, further improvement on promoting satisfaction to a higher level would be beneficial for the elders to maintain regular exercise by using such exercising systems.

According to the result of EGameFlow, the group A outperformed the group B in concentration and immersion. This result is consistent with the results of lower extremity functional fitness training performance and satisfaction although only two constructs show significant differences between the two groups. Except for the way of adjusting exercise intensity, the others in the two groups are identical. Since the group B incorporates the participants' subjective feedback (i.e., rate of perceived exertion, RPE) in the dual adaptive strategy, it is likely the cause of making the group B getting lower scores on concentration and immersion. The subjective feedback provides the participants an opportunity to express their psychological status and helps the adaptive exercising system determine the adjustment of exercise intensity besides movement correctness rate. However, the way of collecting the subjective feedback in this experiment was not a part of the training and could distract the participants. The original scale of RPE is from 6 to 20 (15-point Likert 
scale) and could be further simplified for the elders in such adaptive exercising system to minimize the interference during the training process.

\title{
Conclusions
}

The process of aging is strongly related to one's health, which dependents on the quality of one's life. This study takes the objective assessment (movement correctness rate, $\mathrm{MCR}$ ) and the subjective feedback (rate of perceived exertion, RPE) into the design of the dual adaptive strategy for the training process of functional fitness. With the help of two functional fitness experts, five types of lower extremity movements and a set of exercise intensity levels were developed and validated for the elders specifically. The results of the experiment have demonstrated the elders with the dual adaptive strategy can obtain improvement of training efficiency in elders' lower extremity functional fitness. By concurrently considering elders' physiological and psychological conditions for a body-mind balance, the dual adaptive strategy can help the elders receive training with appropriate exercise intensity levels within a limited training period. On the other hand, human body starts aging in the middle-life and one's body performance will begin going downhill significantly, but the speed of aging is not correlated with gender difference (Milanovic et al., 2013). Maintaining a healthy lifestyle and a habit of regular exercises helps human body to function normally and to slow down the speed of aging (Bherer, Erickson, \& Liu-Ambrose, 2013; Chen, Wang, Yang, \& Liou, 2003; FrankStromborg, Pender, Walker, \& Sechrist, 1990; Litt, Kleppinger, \& Judge, 2002; Rikli \& Jones, 2013; Spirduso \& Cronin, 2001; Walker, Sechrist, \& Pender, 1987; Washburn \& Ficker, 1999). From a practical perspective, the design of lower extremity movements and exercise intensity levels can be applied to create a regular functional fitness training plan for elders along with a satisfied training experience.

Acknowledgments

The authors would like to thank the Ministry of Science and Technology, Taiwan, R.O.C., for financially supporting this research under Grant Nos. MOST-107-2511-H-224-007-MY3, MOST- 106-2511-S-224-005-MY3, and MOST 106-2917-I-564-065

\section{Authors' contributions}

$\mathrm{ICH}$ and SCW designed the study as well as analyzing and interpreting the data. SCW performed the experiment. ICH and SCW were the major contributors in writing the manuscript. YHC, JFY, Kinshuk, and NSC reviewed the manuscript and gave suggestions for editing the paper. The whole process was supported and supervised by NSC. All authors read and approved the manuscript.

\section{Competing interests}

The authors declare that they have no competing interests.

\author{
Author details \\ ${ }^{1}$ Department of Industrial \& Systems Engineering, University of Washington, Seattle, WA 98195, USA. ${ }^{2}$ Department of \\ Information Management, National Sun Yat-sen University, Kaohsiung 80424, Taiwan. ${ }^{3}$ Department of Computer \\ Science, National Chengchi University, Taipei 11605, Taiwan. ${ }^{4}$ Department of Educational Technology, Hangzhou \\ Normal University, Hangzhou, China. ${ }^{5}$ College of Information, University of North Texas, Denton, TX 76201, USA. \\ ${ }^{6}$ Department of Applied Foreign Languages, National Yunlin University of Science and Technology, Yunlin 64002, \\ Taiwan.
}

Received: 6 August 2019 Accepted: 22 October 2019

Published online: 21 November 2019

\section{References}

Aarhus, R., Grönvall, E., Larsen, S. B., \& Wollsen, S. (2011). Turning training into play: Embodied gaming, seniors, physical training and motivation. Gerontechnology, 10(2), 110-120. https://doi.org/10.4017/gt.2011.10.2.005.00.

American College of Sports, M, Chodzko-Zajko, W. J., Proctor, D. N., Fiatarone Singh, M. A., Minson, C. T., Nigg, C. R., Salem, G. J., \& Skinner, J. S. (2009). American College of Sports Medicine position stand. Exercise and physical activity for older adults. Medicine and Science in Sports and Exercise, 41(7), 1510-1530. https://doi.org/10.1249/MSS.0b013e3181a0c95c. 
American Heart Association. (2015). Moderate to vigorous - What is your level of intensity?. http://www.heart.org/HEARTORG/ HealthyLiving/PhysicalActivity/FitnessBasics/Moderate-to-Vigorous-What-is-your-level-of-intensity_UCM_463775_Article.jsp. Retrieved 19 Mar 2017.

Bherer, L., Erickson, K. I., \& Liu-Ambrose, T. (2013). A review of the effects of physical activity and exercise on cognitive and brain functions in older adults. Journal of Aging Research, 2013, 8. https://doi.org/10.1155/2013/657508.

Biddle, S. J., \& Mutrie, N. (2007). Psychology of physical activity: Determinants well-being and interventions (2nd ed.). London: Routledge.

Bieryla, K. A., \& Dold, N. M. (2013). Feasibility of Wii fit training to improve clinical measures of balance in older adults. Clinical Interventions in Aging, 2013(8), 775-781. https://doi.org/10.2147/CIA.S46164.

Bisio, I., Delfino, A., Lavagetto, F., \& Sciarrone, A. (2017). Enabling loT for in-home rehabilitation: Accelerometer signals classification methods for activity and movement recognition. IEEE Internet of Things Journal, 4(1), 135-146. https://doi. org/10.1109/JIOT.2016.2628938.

Bleser, G., Steffen, D., Reiss, A., Weber, M., Hendeby, G., \& Fradet, L. (2015). Personalized physical activity monitoring using wearable sensors. In A. Holzinger, C. Röcker, \& M. Ziefle (Eds.), Smart health: Open problems and future challenges (pp. 99124). Cham: Springer International Publishing. https://doi.org/10.1007/978-3-319-16226-3_5.

Bock, B. C., Dunsiger, S. I., Ciccolo, J. T., Serber, E. R., Wu, W.-C., Tilkemeier, P., Walaska, K. A., \& Marcus, B. H. (2019). Exercise videogames, physical activity, and health: Wii heart fitness: A randomized clinical trial. American Journal of Preventive Medicine, 56(4), 501-511. https://doi.org/10.1016/j.amepre.2018.11.026.

Borg, G. (1970). Perceived exertion as an indicator of somatic stress. Scandinavian Journal of Rehabilitation Medicine, 2(2), 92-98.

Borg, G. (1982). Psychophysical bases of perceived exertion. Medicine and Science in Sports and Exercise, 14(5), 377-381.

Bouwhuis, D. G. (2003). Design for person-environment interaction in older age: A gerontechnological perspective. Gerontechnology, 2(3), 232-246. https://doi.org/10.4017/gt.2003.02.03.002.00.

Brill, P. A. (2004). Functional fitness for older adults. Champaign: Human Kinetics.

Chang, C.-Y., Lai, C.-L., \& Hwang, G.-J. (2018). Trends and research issues of mobile learning studies in nursing education: A review of academic publications from 1971 to 2016. Computers \& Education, 116, 28-48. https://doi.org/10.1016/j. compedu.2017.09.001.

Chen, M. Y., Wang, E. K., Yang, R. J., \& Liou, Y. M. (2003). Adolescent health promotion scale: Development and psychometric testing. Public Health Nursing, 20(2), 104-110.

Chiu, C. M., Hsu, M. H., Sun, S. Y., Lin, T. C., \& Sun, P. C. (2005). Usability, quality, value and e-learning continuance decisions. Computers \& Education, 45(4), 399-416. https://doi.org/10.1016/j.compedu.2004.06.001.

Chung, C.-J., Lai, C.-L., \& Hwang, G.-J. (2019). Roles and research trends of flipped classrooms in nursing education: a review of academic publications from 2010 to 2017. Interactive Learning Environments, 1-22. https://doi.org/10.1080/10494820.2019. 1619589.

Directorate General of Budget Accounting \& Statistics, R. O. C. (2013). Social indicators 2012. Taipei City: The Chinese Statistical Association Retrieved from http://ebook.dgbas.gov.tw/public/Data/31211154738MKFOK1MR.pdf.

Ejupi, A., Gschwind, Y. J., Valenzuela, T., Lord, S. R., \& Delbaere, K. (2016). A Kinect and inertial sensor-based system for the selfassessment of fall risk: A home-based study in older people. Human-Computer Interaction, 31(3-4), 261-293. https://doi. org/10.1080/07370024.2015.1085309.

Fang, W.-C., Sheu, F.-R., Lin, Y.-L., Lee, Y.-L., \& Chen, N.-S. (2015). Interactive physical games: Improving balance in older adults. In M. Chang \& Y. Li (Eds.), Smart learning environments (pp. 159-174). New York: Springer-Verlag. https://doi.org/10.1007/ 978-3-662-44447-4_9.

Fisk, A. D., Rogers, W. A., Charness, N., Czaja, S. J., \& Sharit, J. (2009). Designing for older adults: Principles and creative human factors approaches. Boca Raton: CRC Press.

Fozard, J. L., Rietsema, J., Bouma, H., \& Graafmans, J. A. M. (2000). Gerontechnology: Creating enabling environments for the challenges and opportunities of aging. Educational Gerontology, 26(4), 331-344. https://doi.org/10.1080/036012700407820.

Frank-Stromborg, M., Pender, N. J., Walker, S. N., \& Sechrist, K. R. (1990). Determinants of health-promoting lifestyle in ambulatory cancer patients. Social Science \& Medicine, 31(10), 1159-1168.

Fu, F.-L., Su, R.-C., \& Yu, S.-C. (2009). EGameFlow: A scale to measure learners' enjoyment of e-learning games. Computers \& Education, 52(1), 101-112. https://doi.org/10.1016/j.compedu.2008.07.004.

Gillis, D. E., \& Stewart, A. L. (2005). Physical activity instruction of older adults. In C. J. Jones \& D. J. Rose (Eds.), A new approach to designing exercise programs for older adults (pp. 131-139). Champaign: Human Kinetics.

Green, F., Felstead, A., Gallie, D., Inanc, H., \& Jewson, N. (2013). What has been happening to the training of workers in Britain? LLAKES research paper, Vol. 43. London, UK: Centre for Learning and Life Chances in Knowledge Economies and Societies,

Grewal, G. S., Schwenk, M., Lee-Eng, J., Parvaneh, S., Bharara, M., Menzies, R. A., Talal, T. K., Armstrong, D. G., \& Najafi, B. (2015). Sensor-based interactive balance training with visual joint movement feedback for improving postural stability in diabetics with peripheral neuropathy: A randomized controlled trial. Gerontology, 61(6), 567-574. https:/doi.org/10.1159/ 000371846

Groslambert, A., \& Mahon, A. D. (2006). Perceived exertion: Influence of age and cognitive development. Sports Medicine, 36(11), 911-928. https://doi.org/10.2165/00007256-200636110-00001.

Haigh, R. (1993). The ageing process: A challenge for design. Applied Ergonomics, 24(1), 9-14. https://doi.org/10.1016/00036870(93)90153-Z.

Heywood, S., McClelland, J., Mentiplay, B., Geigle, P., Rahmann, A., \& Clark, R. (2017). Effectiveness of aquatic exercise in improving lower limb strength in musculoskeletal conditions: A systematic review and meta-analysis. Archives of Physical Medicine and Rehabilitation, 98(1), 173-186. https://doi.org/10.1016/j.apmr.2016.08.472.

Hoeger, W. W. K. (1988). Principles and labs for physical fitness and wellness. Englewood: Morton Pub Co..

ljsselsteijn, W., Nap, H. H., de Kort, Y., \& Poels, K. (2007). Digital game design for elderly users. In Paper presented at paper presented at the proceedings of the 2007 conference on future play.

Litt, M. D., Kleppinger, A., \& Judge, J. O. (2002). Initiation and maintenance of exercise behavior in older women: Predictors from the social learning model. Journal of Behavioral Medicine, 25(1), 83-97.

Maillot, P., Perrot, A., \& Hartley, A. (2012). Effects of interactive physical-activity video-game training on physical and cognitive function in older adults. Psychology and Aging, 27(3), 589. 
McAuley, E., Blissmer, B., Marquez, D. X., Jerome, G. J., Kramer, A. F., \& Katula, J. (2000). Social relations, physical activity, and well-being in older adults. Preventive Medicine, 31(5), 608-617. https://doi.org/10.1006/pmed.2000.0740.

Milanovic, Z., Pantelic, S., Trajkovic, N., Sporis, G., Kostic, R., \& James, N. (2013). Age-related decrease in physical activity and functional fitness among elderly men and women. Clinical Interventions in Aging, 8, 549-556. https://doi.org/10.2147/CIA. S44112.

Nap, H. H., Kort, Y. A. W. d., \& IJsselsteijn, W. A. (2009). Senior gamers: Preferences, motivations and needs. Gerontechnology, 8(4), 247-262. https://doi.org/10.4017/gt.2009.08.04.003.00.

Pate, R. R. (1983). A new definition of youth fitness. The Physician and Sportsmedicine, 11(4), 77-83. https://doi.org/10.1080/ 00913847.1983.11708509.

Pruitt, B. A. (2003). Exercise progressions for seniors. Idea Health \& Fitness Source, 21(3), 53-57.

Resnick, B., \& Spellbring, A. M. (2000). Understanding what motivates older adults to exercise. Journal of Gerontological Nursing, 26(3), 34-42.

Rikli, R. E., \& Jones, C. J. (1999). Development and validation of a functional fitness test for community-residing older adults. Journal of Aging and Physical Activity, 7(2), 129-161. https://doi.org/10.1123/japa.7.2.129.

Rikli, R. E., \& Jones, C. J. (2013). Development and validation of criterion-referenced clinically relevant fitness standards for maintaining physical Independence in later years. The Gerontologist, 53(2), 255-267. https://doi.org/10.1093/ geront/gns071.

Sheu, F.-R., Lee, Y.-L., Hsu, H.-T., \& Chen, N.-S. (2015). 6-9 July 2015). Effects of gesture-based fitness games on functional fitness of the elders. In D. G. Sampson, R. Huang, G.-J. Hwang, T.-C. Liu, N.-S. Chen, Kinshuk, \& C.-C. Tsai (Eds.), Proceedings of the 15th IEEE international conference on advanced learning technologies (ICALT 2015) (pp. 158-160). Hualien: IEEE Computer Society.

Sheu, F.-R., Lee, Y.-L., Yang, S.-J., \& Chen, N.-S. (2015). User-centered design of interactive gesture-based fitness video game for elderly. In G. Chen, V. Kumar, Kinshuk, R. Huang, \& S. C. Kong (Eds.), Lecture notes in educational technology. Emerging issues in smart learning (pp. 393-397). Hong Kong: Springer Berlin Heidelberg. https://doi.org/ 10.1007/978-3-662-44188-6_54.

Spirduso, W. W., \& Cronin, D. L. (2001). Exercise dose-response effects on quality of life and independent living in older adults. Medicine and Science in Sports and Exercise, 33(6), 598-608.

Tsai, S.-W., Huang, Y.-H., Chen, Y.-W., \& Ting, C.-T. (2015). Influence of $\beta$-blockers on heart rate recovery and rating of perceived exertion when determining training intensity for cardiac rehabilitation. Journal of the Chinese Medical Association, 78(9), 520-525. https://doi.org/10.1016/j.jcma.2015.05.009.

U.S. Department of Health and Human Services. (1996). Physical activity and health: A report of the surgeon general. Atlanta: U. S. Department of Health and Human Services, Centers for Disease Control and Prevention, National Center for Chronic Disease Prevention and Health Promotion.

Vaziri, D. D., Aal, K., Gschwind, Y. J., Delbaere, K., Weibert, A., Annegarn, J., de Rosario, H., Wieching, R., Randall, D., \& Wulf, V. (2017). Analysis of effects and usage indicators for a ICT-based fall prevention system in community dwelling older adults. International Journal of Human-Computer Studies, 106, 10-25. https://doi.org/10.1016/j.jihcs.2017.05.004.

Walker, S. N., Sechrist, K. R., \& Pender, N. J. (1987). The health-promoting lifestyle profile: Development and psychometric characteristics. Nursing Research, 36(2), 77-81.

Washburn, R. A., \& Ficker, J. L. (1999). Physical Activity Scale for the Elderly.(PASE): The relationship with activity measured by a portable accelerometer. Journal of Sports \& Physical Fitness, 39(4), 336-340.

Wewege, M. A., Thom, J. M., Rye, K.-A., \& Parmenter, B. J. (2018). Aerobic, resistance or combined training: A systematic review and meta-analysis of exercise to reduce cardiovascular risk in adults with metabolic syndrome. Atherosclerosis, 274, 162171. https://doi.org/10.1016/j.atherosclerosis.2018.05.002.

Williams, M. A., Soiza, R. L., Jenkinson, A. M., \& Stewart, A. (2010). EXercising with Computers in Later Life (EXCELL) - pilot and feasibility study of the acceptability of the Nintendo WiFit in community-dwelling fallers. BMC Research Notes, 3(1), 238. https://doi.org/10.1186/1756-0500-3-238.

Yang, G., LV, H., Chen, F., Pang, Z., Wang, J., Yang, H., \& Zhang, J. (2018). A novel gesture recognition system for intelligent interaction with a nursing-care assistant robot. Applied Sciences, 8(12), 2349. https://doi.org/10.3390/app8122349.

Zhao, Y., Chung, P.-K., \& Tong, T. K. (2017). Effectiveness of a balance-focused exercise program for enhancing functional fitness of older adults at risk of falling: A randomised controlled trial. Geriatric Nursing. https://doi.org/10.1016/j.gerinurse. 2017.02.011.

\section{Publisher's Note}

Springer Nature remains neutral with regard to jurisdictional claims in published maps and institutional affiliations. 